\title{
Effect of variations in a reinforcement complex upon reversal shift performance of kindergarten children
}

\author{
WAYNE VINEY, WILLIAM BOYER, and \\ WYNONA VINEY, Colorado State Univer- \\ sity, Fort Collins, Colo. 80521
}

Seventy-two kindergarten children were trained on a two-choice discrimination problem with each correct response being accompanied by a marble and five specifiable stimuli which served as secondary reinforcers. Following initial training, half of the Ss leamed a reversal shift with the specifiable stimuli remaining with the response to the formerly positive cue while the other half learned the reversal with the stimuli shifted to the response to the new positive cue. Within each of these two groups, three stimulus-number $(5,3$, or 1 of the original stimuli) conditions were used. Reversal speed was a negative function of the commonality of the reinforcement complex associated with the training and test tasks.

Typical explanations of variations in reversal shift (RS) learning stress internal processes (e.g., mediational responses, Kendler \& Kendler, 1959; or analyzing mechanisms, Sutherland, 1959) which, by their presence or absence, relate to RS speed and performance factors. Much of the research on RS learning has dealt with parameters which are conveniently interpreted in terms of the presence or absence of these inferred processes. By contrast, there have been few systematic investigations of specifiable external factors which may control RS performance. Examples of manipulable external factors which have been demonstrated to control RS performance include: number of stimulus dimensions common to training and test problems (Fritz \& Blank, 1968); temporal delay between training and test problems(Youniss \& Furth, 1964); and dimensional preference factors (Heal, Bransky, \& Mankinen, 1966). If more accurate and detailed knowledge of RS performance is to be attained it is important to delineate the effects of additional basic stimulus conditions which may bear upon the problem.

The present experiment involved a logical extension of an earlier study (Viney, Hulicka, Raley, Bitner, \& Brewster, 1968) which demonstrated increasing resistance to extinction in kindergarten children as a function of number of stimuli common to both acquisition and extinction sessions. In addition, it was reported that attempted alternative responses in extinction were retarded as the stimulus conditions of acquisition and extinction became increasingly similar. These findings also suggest that alternative responses may be attempted in a RS problem as a function of the commonality between the stimulus conditions of the training and test problems. The present experiment was designed to study the effects of variations in the reinforcement complex associated with training and test tasks.

The typical RS problem involves a training procedure in which $S$ is required to make a discrimination between a positive and negative stimulus. Following this initial task, a second task is introduced in which the formerly positive stimulus becomes negative and the formerly negative stimulus becomes positive. The latter, or RS, task may be regarded as involving both extinction of response to the formerly positive cue and acquisition of response to the new positive cue. Presumably, any process which facilitates extinction, acquisition, or cue sampling in the test problem should facilitate RS performance. RS speed was predicted to be a negative function of the commonality of the reinforcemen complex associated with the training and test tasks.

\section{SUBJECTS}

Thirty-six male and 36 female kindergarten children from three upper-middle. class schools in Fort Collins, Colorado, completed both training and test problems. APPARATUS

The apparatus consisted of a mid-grey aluminum display panel $(20 \times 18$ in.) containing a window (4K in. high $\times 8$ in. wide) in which pairs of stimuli could be presented. The window was centered 4 in. from the top of the panel and an opaque Masonite door could be raised or lowered for purposes of changing the stimuli. To indicate a choice, $S$ could push one of a pair of buttons, each centered $2 \frac{1}{2}$ in. under the stimuli. Two openings and containers into which marble rewards could be delivered via solenoid. operated mechanisms located behind the panel were $1 \frac{1}{2}$ in. from the bottom of the panel and 4 in. from the sides. In addition to the marble, five other stimuli could be presented simultaneously when $S$ made the correct choice. These included: a click resulting from the operation of the delivery mechanism, a red light located 3 in. below the right push button, a green light located
3 in. below the left push button, and a bell and buzzer, located behind the panel. The discriminanda consisted of a black rectangle and circle equated for area (5 sq in.) constructed of plastic Dymo tape centered on $8 \times 4$ Masonite plaques.

\section{PROCEDURE}

Subjects were tested individually in a small quiet room in which $E$ and $S$ were alone. Ss were instructed that they were going to play a game in which they could win marbles, the object of the game being to win a marble on every trial. $E$ then demonstrated how pushing the button could result in the delivery of a marble. $E$ then indicated that at the completion of the game the marbles could be exchanged for a prize at which point $S$ was allowed to inspect an assortment of paper cut-outs consisting of small objects and animals. Upon examination of the prizes, initial discrimination training began. Ss were trained with either the rectangle or circle as positive in the initial training task. In each case the positive stimulus was always accompanied by the five stimuli. The noncorrection procedure was used through out; the learning criterion consisted of nine successive correct responses for both training and test problems. The position of the correct stimulus was varied according to a Gellermann series and the intertrial interval was approximately $5 \mathrm{sec}$. Following training trials Ss immediately began test trials under one of six conditions: Half the Ss learned the RS problem with the stimuli remaining with the formerly positive cue. For the other half, the stimuli were shifted to the new positive cue. One-third of the Ss in each of the above groups received all five of the stimuli, one-third received only three of the stimuli, and one-third received only one of the stimuli. Specific stimulus combinations in the 3 and 1 groups were randomly determined. Ss were also randomly assigned to experimental groups. The design was thus of the 3 by 2 variety with two stimulus locations (either with the formerly positive cue or the new positive cue) and three stimulus-number $(5,3$, or 1$)$ conditions.

\section{RESULTS AND DISCUSSION}

A 3 by 2 analysis of variance indicated equivalence of performance of the six experimental groups on the training problems $(F<1.00$ for both main effects and the interaction). The first analysis conducted on test problem data was based on number of responses to the formerly positive cue before an alternative response was attempted. The effect of the experimental conditions upon these perseverative responses is illustrated in Fig. 1. Because of heterogeneity of variance, the data on which Fig. 1 is based were submitted to a $\log x$ transformation. A 3 by 2 analysis of the transformed data indicated a reliable 


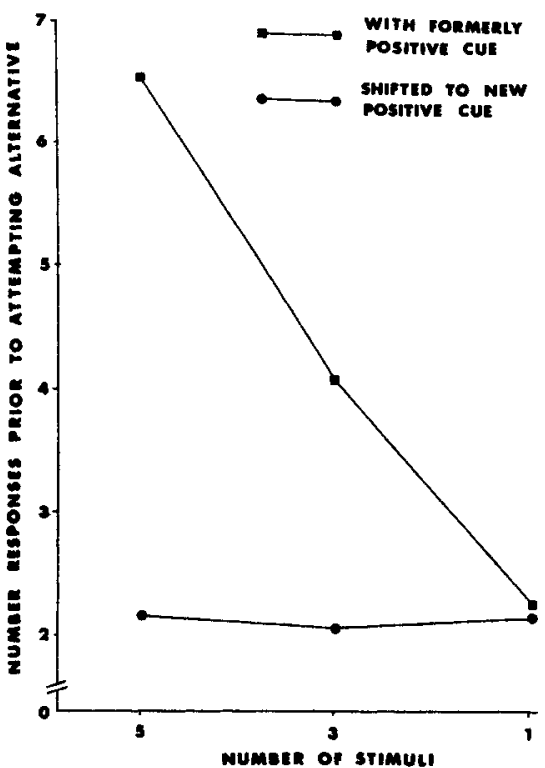

Fig. 1. Number of trials before attempting an alternative response as a function of number and location of stimuli.

stimulus location effect ( $F=6.50$, df $=1 / 66, p<.02)$ with attempts to try alternative responses being retarded when the stimuli remained with the formerly positive cue. Tests of the effects of number of stimuli and Number by Location interaction were not significant. The effect of number appears random when stimuli are shifted to the new positive cue. When, however, the stimuli remain with the formerly positive cue there is an apparent number effect.

The second analysis was conducted on the number of trials to achieve RS criterion in the test problems. These data are presented in Table 1 . A 3 by 2 analysis again indicated a significant $(F=5.95, \mathrm{df}=1 / 66, \mathrm{p}<.02)$ location effect revealing a negative relationship between RS speed and commonality of the reinforcement complex associated with the training and test problems. Results related to number of stimuli appear similar to those obtained for the data on number of responses prior to attempting an alternative. One exception, likely due to random variation, occurred with the apparently inflated mean of the group receiving one stimulus with the formerly positive cue.

Table 1

Means and SDs of Trials to Criterion for Groups Varying in Terms of Number and Location of Stimuli

\begin{tabular}{llrrrr}
\hline Location of & & \multicolumn{3}{c}{ Number of stimuli } \\
stimuli & & \multicolumn{2}{c}{5} & \multicolumn{1}{c}{3} & \multicolumn{1}{c}{1} \\
\hline With formeriy & M & 17.33 & 13.00 & 15.25 \\
positive cue & SD & 14.14 & 10.07 & 11.31 \\
Shifted to new & M & 8.83 & 7.58 & 10.17 \\
positive cue & SD & 7.50 & 8.04 & 10.82 \\
\hline
\end{tabular}

Variation in the reinforcement complex significantly alters RS performance possibly by increasing the probability of cue sampling in the test problem and reducing the number of perseverative errors. These results suggest that it might be interesting to examine the effect of stimulus variation factors which may relate to other aspects of the experimental situation. For example, in many studies, there is considerable stimulus variation associated with changes in the discriminanda utilized in training and test problems. Perhaps the greater the similarity between the discriminanda associated with both training and test problems, the slower the learning of the test problems. Such a prediction is important to studies which attempt to compare RS learning with nonreversal shift (NRS) learning. If, as is often the case, the discriminanda associated with both training and test tasks are more homogeneous for one kind of shift than another, then comparisons between shifts would be meaningful only in terms of stimulus variation factors. Variations in

\section{Learning time with a mnemonic system}

EDWARD BERLA, J. J. PERSENSKY, and R. J. SENTER, University of Cincinnati, Cincinnati, Ohio 45221

Subjects trained in the use of a commercial mnemonic technique ("hook" or "peg" system) and Ss trained by a traditional rote procedure were tested on the total time required to learn a list of 20 concrete nouns. Mnemonically trained Ss learned the list in significantly less time than did rote-control Ss. Results do not support the "total time" hypothesis.

According to Yates (1966) general mnemonic systems have existed since the golden age of Greece. Several modern authors of commercial texts (Furst, 1949, 1957; Lorayne, 1957; Roth, 1961) have claimed general utility for mnemonic techniques as aids to rote learning. $A$ basic part of all commercial mnemonic systems is a "hook" or "peg" system which consists of a highly overlearned list of common nouns memorized in a coded sequence. On subsequent learning of new lists, $S$ merely has to associate each new word with the appropriate word in the previously overleamed list. This association is typically accomplished by forming a "bizarre" mental discriminanda associated with training and test tasks in both RS and NRS problems are currently being investigated.

\section{REFERENCES}

FRITZ, B., \& BLANK, M. Role of the irrelevant cue in rapid reversal learning in nursery school children. Journal of Comparative \& Physiological Psychology, 1968, 65, 375-378.

HEAL, L. W., BRANSKY, M. L., \& MANKINEN, R. L. The role of dimension preference in reversal and nonreversal shifts of retardates. Psychonomic Science, 1966, 6, 509-510.

KENDLER, T. S., \& KENDLER, H. H. Reversal and nonreversal shifts in kindergarten children. Journal of Experimental Psychology, 1959, 58, 56-60.

SUTHERLAND, N. S. Stimulus analyzing mechanisms. In Proceedings of a symposium on the mechanization of thought processes. Vol. 2. London: Her Majesty's Stationery Office, 1959. YOUNISS, J., \& FURTH, H. G. Reversal learning in children as a function of overtraining and delayed transfer. Journal of Comparative \& Physiological Psychology, 1964, 57, 155-157. VINEY, W., HULICKA, I., BITNER, J., RALEY, C. L., \& BREWSTER, P. Effect of stimulus variation upon resistance to extinction in kindergarten children. Journal of Comparative \& Physiological Psychology, 1968, 65, 539-541. image involving both a previously overlearned word (called a "hook" or "peg") and the new word. During recall S retrieves the new word from memory by retrieving the "hook" or "peg" to which the new word is "attached." This retrieval of the "hook" is supposed to produce automatic retrieval of the newly associated word.

There has been little formal experimental investigation of mnemonic techniques. Wood (1967) conducted experiments in which Ss were presented a list of printed "hooks" to be used as mediators in the learning of a different list of common nouns. The results showed that Ss who were instructed how to use the "hook" words as mediators recalled significantly more words than Ss who were not so instructed or who did not have the printed "hooks."

Senter \& Hauser (1968) required Ss to remember mnemonic "hooks" rather than allowing visual access to the "hooks" in printed form. Ss who were trained in the use of mnemonics performed significantly better in the number of CVC items they could correctly anticipate as compared to untrained Ss using CVC items of the same association value.

These, and other studies (Persensky \& Senter, in press; Ross \& Lawrence, 1968), have suggested that the use of general 